\title{
Sero-prevalence and intrinsic factors associated with Brucella infection in food animals slaughtered at abattoirs in Abuja, Nigeria
}

\author{
Mabel Kamweli Aworh ${ }^{1,2^{*}}$, Emmanuel Chukuwdi Okolocha ${ }^{3}$, Emmanuel Jolaoluwa Awosanya ${ }^{4}$ \\ and Folorunso Oludayo Fasina ${ }^{5}$
}

\begin{abstract}
Background: Brucellosis, a neglected tropical food-borne zoonotic disease, has a negative impact on both animal and human health as well as tremendous socio-economic impact in developing countries where rural income relies largely on livestock breeding and dairy products. It is endemic in the animal population in Nigeria and is a recognized occupational hazard. This work was done to establish the sero-prevalence and predisposing factors of food animals in Abuja, Nigeria to Brucella infection.

Results: Of 376 cattle, 203 sheep and 260 goats screened, 21 (5.6\%); 19 (9.4\%); 51 (19.6\%) were positive, respectively for brucellosis with Rose Bengal Plate Test, and $2(0.5 \%) ; 4(2.0 \%) ; 10$ (3.8\%), respectively with c-ELISA. The likelihood of acquiring Brucella infection was higher among the Red Sokoto breed of goats compared to other breeds of goats $(p=0.05)$.

Conclusion: This study showed that the prevalence of Brucella infection was low in food animals slaughtered at abattoirs in Abuja. However, of all animals screened, seropositivity to Brucella infection was highest in goats with Red Sokoto breed of goats more likely to acquire the disease when compared to other breeds.
\end{abstract}

Keywords: Brucellosis, Predisposing factors, Abattoir, Nigeria

\section{Background}

Brucellosis also known as undulant fever is a neglected bacterial zoonosis of public health importance in Africa and certain parts of the world. This disease in animals has been eradicated in Australia, Canada, Europe, Israel, Japan and New Zealand [1]. It is also listed among the seven neglected zoonoses by the World Health Organization (WHO). Brucellosis has impacted greatly on both human and animal health with severe and tremendous socio-economic impacts, particularly in the developing

\footnotetext{
*Correspondence: mabelaworh@yahoo.com

${ }^{1}$ Department of Veterinary \& Pest Control Services, Federal Ministry of Agriculture \& Rural Development, FCDA Secretariat, Area 11, Garki, Abuja, Nigeria

Full list of author information is available at the end of the article
}

countries where rural incomes depend heavily on livestock breeding and dairy products [2].

Of all the species of Brucella: B. abortus, B. canis, B. melitensis and $B$. suis are of public health importance. However, two species $B$. melitensis and B. suis have been reported to be more virulent in humans than $B$. abortus and B. canis. It is important to note that serious complications can occur with any of these species of Brucella [3].

Brucellosis, a foodborne zoonosis has caused considerable morbidity in humans in many parts of the world with major impacts on young children and elderly people [3]. People are at high risk of getting infected by drinking unpasteurized milk which is readily sold in parts of the country [4]. A recent study on brucellosis in the Federal 
Capital Territory (FCT), Abuja reported a sero-prevalence of $24.1 \%$ in abattoir workers [5].

In animals, it is endemic in most countries in Africa including Nigeria [6,7] with a prevalence of $16.2 \%$ in slaughtered cattle population in sub-Saharan Africa [8] and $3.5 \%$ in Nigeria $[9,10]$. The prevalence of the disease in slaughtered ruminants in Plateau State, Nigeria is higher and widespread (sheep, 14.5\% and goats, 16.1\%) [11]. Cadmus et al. have earlier reported a prevalence of $5.8 \%$ in cattle and $0.9 \%$ in goats in South Western Nigeria [12]. Previous studies have confirmed the problem of brucellosis in livestock with evidence of widespread infection in most parts of the country and attendant economic consequences $[2,10,13-16]$. Specifically, the serological prevalence obtained in different parts of Nigeria from different animal species ranged from 0.20 to $79.70 \%$ [12].

\section{Purpose of the study}

Assessment of the prevalence of Brucella infection in food animals at abattoirs in some parts of Nigeria has been reported by very few researchers [17]. However in FCT, Abuja there is the paucity of data on the prevalence of Brucella infection and associated factors in food animals slaughtered at the abattoirs. The current study focuses on its intrinsic determinants in ruminants (cattle, sheep, and goats) slaughtered in two abattoirs in FCT, Abuja from June to August 2011 in order to provide indications about the extent of the problem in this study area. The main objective of this work was to determine the sero-prevalence and associated intrinsic factors with seropositivity to Brucella spp. in food animals (cattle, sheep, and goats) slaughtered at the abattoirs.

\section{Methods}

\section{Study sites}

Two abattoirs with the highest population of food animals slaughtered on a daily basis were selected as study areas out of the five abattoirs across Abuja. This information was provided by the FCT Department of Agriculture and Rural Development. Karu abattoir (government owned) and Dei-Dei abattoir (privately-owned) were selected as study sites (Fig. 1).

\section{Study design}

We conducted a cross-sectional study to determine the sero-prevalence of B. abortus and B. melitensis antibodies in sera of food animals slaughtered in the selected abattoirs. We also conducted an analytic cross-sectional study to establish the predisposing factors to Brucella infection in food animals.

\section{Study population}

This comprised all cattle, sheep, and goats slaughtered at Karu abattoir and Dei-Dei abattoir at the time of the study.

\section{Sample size determination}

The sample size was determined based on total population of food animals at the time of study with expected Brucella positive proportions of $32 \%$ in cattle [18], sheep (14.5\%) and goats $(16.1 \%)$ [11], $q=1-p, 5 \%$ error margin and $95 \%$ confidence level (CI). Using $n=Z^{2} p q / d^{2}$, where $p=32 \%$ and $\mathrm{q}=0.68$ for cattle, $14.5 \%$ and 0.86 for sheep and $16.1 \%$ and 0.84 for goats, $\mathrm{z}=1.96, \mathrm{~d}=0.05,10 \%$ non-response rate, the sample size was calculated and the following values were arrived at: cattle, $n=376$; sheep, $n=203$; goats, $n=260$.

\section{Sampling method and data collection}

Food animals slaughtered at these two abattoirs were included in the study. We used systematic random sampling with a sampling interval of four to select the food animals. We selected 18 cattle, 10 sheep and 13 goats per day until the sample size was obtained. Data on each species such as breed and sex were obtained through direct observation at the time of sample collection.

\section{Laboratory analysis \\ Sources of reagents}

Brucella abortus (standard antigen, product code RAA0060) and B. melitensis (sensitive antigen, product code RAA2016) antigens for Rose Bengal Plate Test, sourced from Veterinary Laboratory Agency and OIE referral laboratory for Brucellosis, Weybridge, United Kingdom were used to screen cattle and sheep/ goats respectively. Competitive Enzyme-linked Immunosorbent Assay (COMPELISA-400, product code RAI2006) kit also sourced from Veterinary Laboratory Agency, United Kingdom was used to screen all the animals.

\section{Samples collection}

Blood was collected aseptically from all food animals: cattle, sheep, and goats by a qualified veterinarian under strict hygienic conditions at the point of slaughter using sterile sample bottles. Five milliliter of blood from each animal was collected into a labeled, clean, sterile bottle and kept in slanted position on an ice-pack to clot for about an hour. Clear sera were separated from the clotted blood by decanting and further centrifuging at approximately $1000 \mathrm{~g}$ for $10 \mathrm{~min}$. A Pasteur pipette was used to apportion serum into labeled sterile sample bottles and stored at $-20^{\circ} \mathrm{C}$ until needed for analysis. 


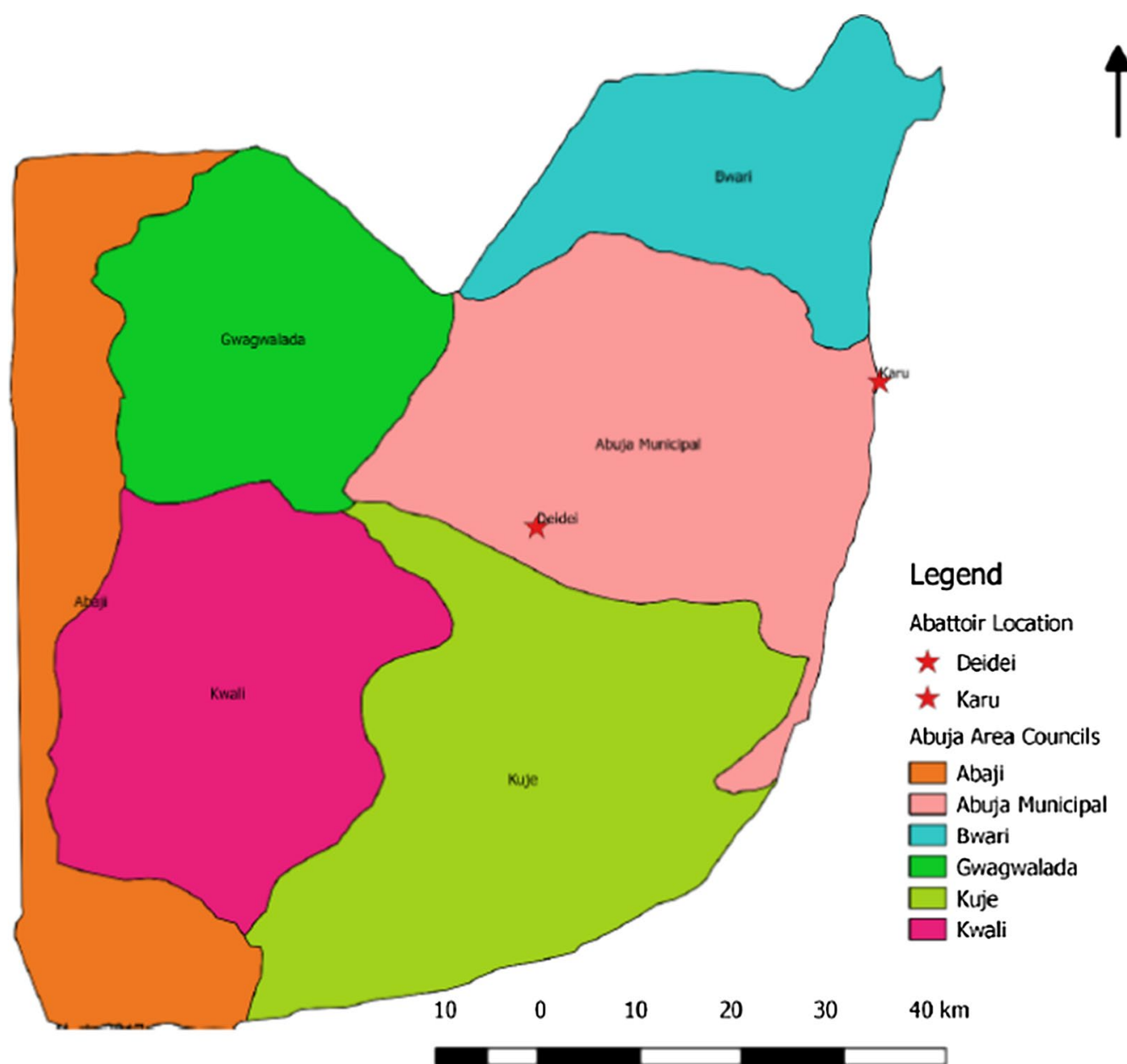

Fig. 1 Map of Abuja showing the study area. This map highlights the six area councils in different colour codes namely: Abaji, Bwari, Kwali, Kuje, Gwagwalada and Abuja Municipal area councils. Our study was done at two abattoirs with high volume of daily slaughter of food animals (Karu, a government owned abattoir and Dei-Dei, a privately owned abattoir) located in the Abuja Municipal area council. (Source of the Map is the Federal Ministry of Agriculture and Rural Development, Abuja, Nigeria)

\section{Serological testing of food animals}

\section{Rose Bengal Plate Test (RBPT)}

We labeled each serum sample with a permanent marker and each was screened for B. abortus and B. melitensis antibodies using RBPT. The tests were done using the standard operating procedures provided in the OIE Manual of Diagnostic Tests and Vaccines for Terrestrial Animals [19]. The antigen and serum samples were brought to $22 \pm 4{ }^{\circ} \mathrm{C}$ and $25-30 \mu$ of each sample was placed on a white ceramic tile. The antigen bottle was gently shaken to ensure homogeneity and the same volume of antigen was mixed with each serum spot using a clean wooden rod for each test producing a circular zone. The mixture was gently agitated at room temperature on a rocker for about $4 \mathrm{~min}$. It was read for agglutination immediately after the rocking was completed. Any visible agglutination reaction was considered to be positive. Agglutination reactions were interpreted as positive RBPT result for the affected animal.

\section{Competitive enzyme linked immunosorbent assay (c-ELISA) method}

The c-ELISA kit used was COMPELISA 400 for brucellosis diagnosis sourced from Veterinary Laboratory Agency, Surrey, United Kingdom. COMPELISA 400 which detects antibodies to smooth Brucella species was used to test the food animals (cattle, sheep, and goats) for Brucella antibodies. We constituted the reagents in the kit as directed by the manufacturers and performed the c-ELISA tests using the manufacturer's protocol (Product code RAI2006). Test readings were taken at a wave length of $450 \mathrm{~nm}$ using a spectrophotometer Multiskan ${ }^{\circledR}$ ELISA 
reader (Thermo Scientific, USA). A positive result was obtained when a sample showed optical density $\leq 60 \%$ of the mean optical density of conjugate control wells [20].

\section{Statistical analysis}

We entered, cleaned and analyzed data collected using Epi Info version 7 software. We determined proportions and compared the differences in sero-positive and seronegative animals using Chi square tests and odds ratio (OR) for the investigated variables. We considered our test results as significant if the $p$ value was $\leq 0.05$.

\section{Results}

\section{Sero-prevalence of food animals}

Sero-prevalence of food animals to Brucella infection varied from one abattoir to the other with the highest in cattle recorded at Karu abattoir. However, the highest sero-prevalence in sheep and goats was recorded at Dei-Dei abattoir. Overall 91 (10.8\%) food animals were observed to be positive for brucellosis, among these 21 (2.5\%) were cattle, $19(2.3 \%)$ were sheep and $51(6 \%)$ were goats (Table 1). Out of a total of 376 cattle screened at both abattoirs for B. abortus, 21 (5.6\%) and two (0.5\%) were positive for brucellosis by RBPT and c-ELISA, respectively. Of the 203 sheep screened for $B$. melitensis, 19 (9.4\%) and four (2.0\%) were positive for brucellosis by RBPT and c-ELISA respectively. Also out of a total of 260 goats screened for B. melitensis, 51 (19.6\%) and ten (3.8\%) were positive for brucellosis by RBPT and c-ELISA respectively. Among the food animals screened, the highest prevalence of Brucella infection was observed in goats both at Dei-Dei (22.3\%) and Karu (16.9\%) abattoirs in Abuja. The overall sero-prevalence in cattle, sheep, and goats was 5.6, 9.4 and $19.6 \%$ respectively (Fig. 2).

\section{Risk factors associated with sero-prevalence in food} animals

Factors associated with seropositivity to Brucella infection in the various food animals screened at Karu and Dei-Dei abattoirs in FCT are shown in Table 2. The only factor associated with Brucella infection in these food animals was the breed especially in goats $(\mathrm{p}=0.05)$. The Red Sokoto breed of goats was more likely to acquire Brucella infection when compared to goats that were crossbred $([\mathrm{OR}=5.9 ; \mathrm{CI}=1.0-125.0] \mathrm{p}=0.05)$.

\section{Discussion}

Our findings show that seropositivity to Brucella infection in food animals was highest among the goats when compared to cattle and sheep; this agrees with the results of Ahmed et al. where the seropositivity recorded in goats was 1.6 times higher than that of sheep [21]. Bertu et al. also reported a high sero-prevalence of $16.1 \%$ in goats in Plateau State, Nigeria [22]. Another recent study in Benue State, Nigeria by Ogugua et al. also supports our finding as the study reported a prevalence of $17.3 \%$ in goats [23]. The high seropositivity in goats may be due to the ability of the goats to shed Brucella organisms for long periods either in vaginal discharges or milk [24]. This has serious public health implications because of the zoonotic nature of the disease especially among abattoir workers who lack personal protective equipment, indulge in risky practices and are in close proximity with these food animals at the abattoirs [5].

This study showed that seropositivity to Brucella infection in cattle was low; consistent with findings of Cadmus et al. in Ibadan, Nigeria [25]. Our findings also revealed lower seropositivity to Brucella infection in sheep when compared to results from Bertu et al. in a sero-epidemiology survey of brucellosis in small ruminants which reported a higher sero-prevalence in sheep. Osman et al. in a similar study also reported a low prevalence of brucellosis in sheep which was consistent with findings from this study [26].

The only factor associated with Brucella infection in food animals observed in this study was that related to the breed of the animals especially in goats probably due to genetic variation which is an important factor in conferring resistance or tolerance to certain types to diseases [17]. This finding is in contrast to the reports of Mai

Table 1 Sero-prevalence of Brucella infection in food animals slaughtered in two abattoirs in FCT, Abuja, Nigeria

\begin{tabular}{|c|c|c|c|c|c|c|}
\hline Abattoirs & Species & Total & RBPT positive & $\%$ & c-ELISA positive & $\%$ \\
\hline \multirow[t]{3}{*}{ Karu } & Cattle & 180 & 19 & 10.6 & 2 & 1.1 \\
\hline & Sheep & 76 & 5 & 6.6 & 2 & 2.6 \\
\hline & Goats & 130 & 22 & 16.9 & 2 & 1.5 \\
\hline \multirow[t]{3}{*}{ Dei-Dei } & Cattle & 196 & 2 & 1.0 & 0 & 0 \\
\hline & Sheep & 127 & 14 & 11.0 & 2 & 1.5 \\
\hline & Goats & 130 & 29 & 22.3 & 8 & 6.2 \\
\hline Total food animals & & 839 & 91 & 10.8 & 16 & 1.9 \\
\hline
\end{tabular}




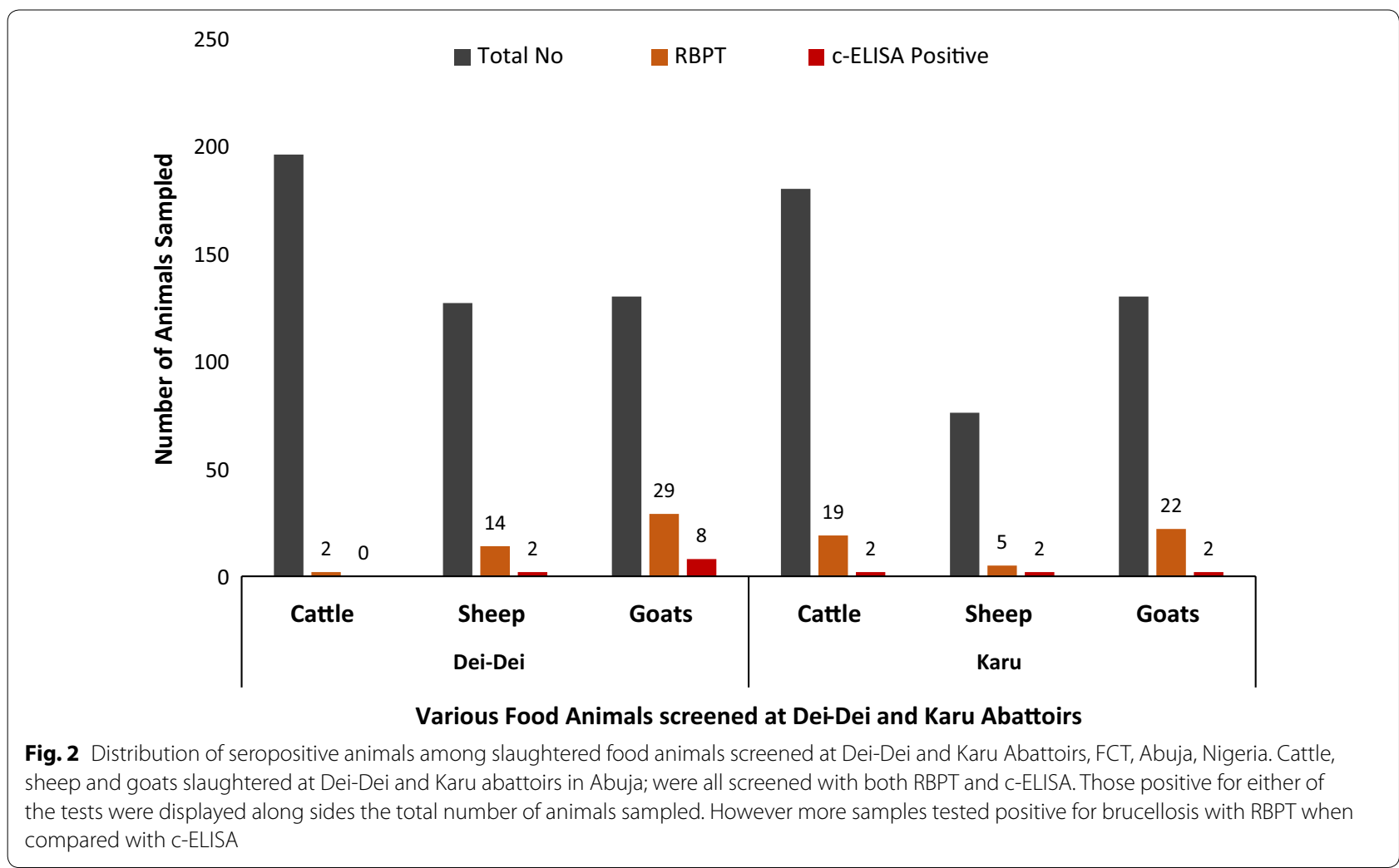

Table 2 Predisposing factors associated with Brucella seropositivity in food animals slaughtered at Karu and Dei-Dei abattoirs in FCT

\begin{tabular}{|c|c|c|c|c|c|}
\hline Species & Characteristics & Sero-positive animals (\%) & Sero-negative animals (\%) & OR $(95 \% \mathrm{Cl})$ & p-value \\
\hline \multirow[t]{7}{*}{ Cattle } & Breed & & & & \\
\hline & White Fulani & $5(3.6)$ & $132(96.4)$ & Ref. & \\
\hline & Red Bororo & $8(5.7)$ & $132(94.3)$ & $1.6(0.5,5.5)$ & 0.42 \\
\hline & Sokoto Gudali & $8(8.1)$ & $91(91.9)$ & $2.3(0.7,8.0)$ & 0.14 \\
\hline & Sex & & & & \\
\hline & Male & $20(5.8)$ & $326(94.2)$ & $1.8(0.3,38.5)$ & 0.58 \\
\hline & Female & $1(3.3)$ & $29(96.7)$ & Ref. & \\
\hline \multirow[t]{7}{*}{ Sheep } & Breed & & & & \\
\hline & Ouda & $6(9.8)$ & $55(90.2)$ & Ref. & \\
\hline & Yankasa & $13(10.9)$ & $106(89.1)$ & $1.1(0.4,3.4)$ & 0.82 \\
\hline & Balami & $0(0.0)$ & $23(100.0)$ & $0.0(0.0,1.7)$ & 0.12 \\
\hline & Sex & & & & \\
\hline & Male & $5(8.5)$ & $54(91.5)$ & $0.9(0.3,2.5)$ & 0.78 \\
\hline & Female & $14(9.7)$ & $130(90.3)$ & Ref. & \\
\hline \multirow[t]{6}{*}{ Goats } & Breed & & & & \\
\hline & Red Sokoto & $50(21.1)$ & $187(78.9)$ & $5.9(1.0,125.0)$ & $0.05^{*}$ \\
\hline & Cross breed & $1(4.3)$ & $22(95.7)$ & Ref. & \\
\hline & Sex & & & & \\
\hline & Male & $34(17.6)$ & $159(82.4)$ & $0.6(0.3,1.2)$ & 0.17 \\
\hline & Female & $17(25.4)$ & 50 (74.6) & Ref. & \\
\hline
\end{tabular}

*Values that are significant at $p \leq 0.05$ 
et al. that brucellosis in animals is not breed specific [15]. However, findings from our study were consistent with that of Ogugua et al. who reported that breeds of goats were an important factor in determining sero-prevalence to Brucella infection as his study showed that high infection rates were observed among the Red Sokoto breeds of goats [23].

Predisposing factors reported by other studies for seropositivity to Brucella infection in cattle are breed and sex of animals [17]. Other studies reported that sex of the animals was a risk factor for seropositivity to Brucella infection [27, 28]. However, this study did not establish any association between sex of animals and seropositivity to Brucella infection probably because a low percentage of the food animal screened were seropositive to the Brucella organism. This finding is consistent with reports of Muma et al. in a study on risk factors for Brucellosis in ruminants reared in Zambia [29].

There appears to be a marked difference in the number of sero-positives detected by RBPT and c-ELISA in this study. This may be due to the stage of Brucella infection in the food animals as RBPT are usually more sensitive in detecting early Brucella infection than the c-ELISA test [30].

This study has limitations as we were unable to collect data on animal origin, age and gestational status of each animal slaughtered at the abattoir because the original animal owners were not present at the time of the study.

\section{Conclusion}

The sero-prevalence of brucellosis among food animals slaughtered at abattoirs in Abuja was low. Of all the food animals screened, the highest seropositivity was recorded in goats. The breed of goats' especially Red Sokoto breeds was an important factor associated with seropositivity for brucellosis in food animals. The following recommendations were made to the relevant authorities based on the results from our study: The need for regular surveys on brucellosis to be organized by Government at all levels among food animals slaughtered at the abattoirs as a lot of data could be generated for its control and eradication. The application of test-and-slaughter methods especially in the small ruminant population would further strengthen the control and eradication of brucellosis. Future work is also being recommended to focus on the origin of the goats slaughtered at these abattoirs so as to generate specific information to the government on caprine brucellosis outbreak hot-spots in the country.

\section{Abbreviations}

B: Brucella; c-ELISA: competitive ELISA; FCT: Federal Capital Territory; OIE: World Organization for Animal Health; RBPT: Rose Bengal Plate Test; WHO: World Health Organization.

\section{Authors' contributions}

EO made substantial contributions to conception and design. MA was the principal investigator, designed data collections tools, collected data, analyzed and interpreted the data. FF assisted in data collection and laboratory analysis. EA and FF revised article critically for important intellectual content. All authors read and approved the final manuscript.

\section{Author details \\ ${ }^{1}$ Department of Veterinary \& Pest Control Services, Federal Ministry of Agriculture \& Rural Development, FCDA Secretariat, Area 11, Garki, Abuja, Nigeria. ${ }^{2}$ Nigeria Field Epidemiology and Laboratory Training Programme, Abuja, Nigeria. ${ }^{3}$ Department of Veterinary Public Health and Preventive Medicine, Ahmadu Bello University, Zaria, Nigeria. ${ }^{4}$ Department of Veterinary Public Health and Preventive Medicine, University of Ibadan, Ibadan, Nigeria. \\ ${ }^{5}$ Department of Production Animal Studies, Faculty of Veterinary Science, University of Pretoria, Onderstepoort, South Africa.}

\section{Acknowledgements}

The authors would like to appreciate Dr. Judy Stack of FAO/WHO Collaborating Centre for Research on Brucellosis, Weybridge, United Kingdom for donating the Rose Bengal Plate Test reagents and COMPELISA 400 kits used for this research. The authors also acknowledge the intellectual contributions of Nigeria Field Epidemiology \& Laboratory Training Programme (NFELTP) Facilitators towards the success of this research.

\section{Competing interests}

The authors declare that they have no competing interests.

Availability of supporting data

Data can be made available by the corresponding author when requested.

Consent to publish

Not applicable.

\section{Funding}

Funding for this research was provided by the Human Animal Interface Project, African Field Epidemiology network/US Centers for Disease Control and Prevention.

\section{Publisher's Note}

Springer Nature remains neutral with regard to jurisdictional claims in published maps and institutional affiliations.

Received: 9 February 2017 Accepted: 30 September 2017

Published online: 10 October 2017

References

1. Hadush A, Pal M. Brucellosis_an infectious re-emerging bacterial zoonosis of global importance. Int J Livest Res. 2013;3(1):28-34.

2. Ducrotoy M, Bertu W, Ocholi R, Gusi A, Bryssinckx W, Welburn S, Moriyón I. Brucellosis as an emerging threat in developing economies: lessons from Nigeria. PLoS Negl Trop Dis. 2014;8(7):e3008.

3. Corbel MJ. Brucellosis in humans and animals. World Organisation for Animal Health [Internet]. 2006. http://www.who.int/csr/resources/publications/Brucellosis.pdf. Cited 31 Jul 2017.

4. Katafiasz AR, Bartett P. Motivation for unpasteurized milk consumption in Michigan, 2011. Food Prot Trends [Internet]. 2012;32(3):124-8. http://www. foodprotection.org/files/food-protection-trends/Mar-12-Bartlett.pdf.

5. Aworh M, Okolocha E, Kwaga J, Fasina F, Lazarus D, Suleman I, Poggensee G, Nguku P, Nsubuga P. Human brucellosis: seroprevalence and associated exposure factors among abattoir workers in Abuja, Nigeria-2011. Pan Afr Med J. 2013;16:103. doi:10.11604/pamj.2013.16.103.2143.

6. Akinseye VO, Adesokan HK, Ogugua AJ, Adedoyin FJ, Otu PI, Kwaghe A V., et al. Sero-epidemiological survey and risk factors associated with bovine brucellosis among slaughtered cattle in Nigeria. Onderstepoort J Vet Res [Internet]. 2016;83(1):7. http://ojvr.org/index.php/ojvr/article/view/1002. Cited 1 Aug 2017 
7. Ducrotoy M, Bertu WJ, Matope G, Cadmus S, Conde-Álvarez R, Gusi AM, Moriyón I. Brucellosis in sub-Saharan Africa: current challenges for management, diagnosis and control. Acta Trop. 2015;165:179-93. doi:10.1016/j.actatropica.2015.10.023.

8. Mangen, M.-J., Otte, J., Pfeiffer, D., \& Chilonda, P. (2002). Bovine brucellosis in sub-Saharan Africa: estimation of sero-prevalence and impact on meat and milk off-take potential. FAO Livest Policy Discuss Pap No. 8, (8): 58.

9. Bwala D, McCrindle C, Fasina O, ljagbone I. Abattoir characteristics and seroprevalence of bovine brucellosis in cattle slaughtered at Bodija Municipal Abattoir, Ibadan, Nigeria. J Vet Med Anim Heal. 2015;7(5):164-8.

10. Olayinka O, Ishola, Ogundipe GAT. Seroprevalence of brucellosis in trade cattle slaughtered in Ibadan, Nigeria. Bull Anim Heal Prod Afr. 2000;48(1):53-5.

11. Ogugua AJ, Akinseye VO, Ayoola MC, Oyesola OO, Shima FK, Tijjani AO, et al. Seroprevalence and risk factors of brucellosis in goats in selected states in Nigeria and the public health implications. Afr J Med Med Sci [Internet]. 2014;43(Suppl 1):121-9. https://www.ncbi.nlm.nih.gov/pmc/ articles/PMC4682909/pdf/nihms-654982.pdf. Cited 1 Aug 2017.

12. Kaltungo B, Saidu S, Sackey A, Kazeem H. Serological evidence of Brucellosis in goats in Kaduna North Senatorial District of Kaduna State, Nigeria. ISRN Veterinary Science. 2013. http://dx.doi.org/10.1155/2013/963673. Accessed 10 July 2013.

13. Bano Y, Lone SA. Brucellosis: an economically important infection. J Med Microbiol Diagn. 2015;4:208. doi:10.4172/2161-0703.1000208.

14. Singh B, Dhand N, Gill J. Economic losses occurring due to brucellosis in Indian livestock populations. Prev Vet Med. 2015;119(3):211-5.

15. Mai H, Irons P, Kabir J, Thompson P. A large seroprevalence survey of brucellosis in cattle herds under diverse production systems in northern Nigeria. BMC Vet Res. 2012;8:144

16. McDermott J, Grace D, Zinsstag J. Economics of brucellosis impact and control in low-income countries. Rev Sci Tech Off Int Epiz. 2013;32(1):249-61.

17. Akinseye V, Adesokan H, Ogugua A, Adedoyin F, Otu P, Kwaghe A Kolawole N, Okoro O, Agada C, Tade A, Faleke O, Okeke A, Akanbi I, Ibitoye M, Dipeolu M, Dale E, Lorraine P, Taylor A, Awosanya E, Cadmus S, Stack J. Sero-epidemiological survey and risk factors associated with bovine brucellosis among slaughtered cattle in Nigeria. Onderstepoort J Vet Res. 2016;83(1):a1002

18. Junaidu A, Oboegbulem S, Salihu M. Seroprevalence of brucellosis in prison farm in Sokoto, Nigeria. Asian J Epidemiol. 2008;1:24-8.

19. World Organisation for Animal Health. Manual of diagnostic tests and vaccines for terrestrial animals (mammals, birds and bees) 6 th ed,Vol I, 1989. Foreword [Internet]. Vol. II III, 3rd ed, 4th ed, 2008. http://www.oie. int.

20. COMPELISA $160 \& 400$ A competitive ELISA kit for the detection of antibodies against Brucella in serum samples www.aphascientific.com
Safety Urea $\mathrm{H}_{2} \mathrm{O}_{2}$ CAS 124-43-6. Instructions for use (for in vitro and animal use only). https://zelsbrucellosis.files.wordpress.com/2015/07/ compelisa-ifuv8-word-new-logo.pdf. Accessed 11 July 2017.

21. Ahmed MO, Elmeshri SE, Abuzweda AR, Blauo M, Abouzeed YM, Ibrahim A, et al. Seroprevalence of brucellosis in animals and human populations in the western mountains region in Libya, December 2006-January 2008. Euro Surveill [Internet]. 2010;15(30). http://www.ncbi.nlm.nih.gov/pubmed/20684813. Cited 2 Aug 2010.

22. Bertu WJ, Ajogi I, Bale JOO, Kwaga JKP, Ocholi RA. Sero-epidemiology of brucellosis in small ruminants in Plateau State, Nigeria. Afr J Microbiol Res [Internet]. 2010;4(19):1935-8. http://www.academicjournals.org/ajmr. Cited 2 Aug 2017

23. Ogugua AJ, Akinseye VO, Ayoola MC, Oyesola OO, Shima FK, Tijjani AO, et al. Seroprevalence and risk factors of brucellosis in goats in selected states in Nigeria and the public health implications. Afr J Med Med Sci [Internet]. 2014;43(Suppl 1):121-9. http://www.ncbi.nlm.nih.gov/pubmed/26689681. Cited 2 Aug 2017.

24. Poester F, Samartino L, Santos R. Pathogenesis and pathobiology of brucellosis in livestock. Rev Sci Tech Off Int Epiz. 2013;32(1):105-15.

25. Cadmus SIB, ljagbone IF, Oputa HE, Adesokan HK SJ. Serological survey of brucellosis in livestock animals and workers in Ibadan, Nigeria. Afr J Biomed Res [Internet]. 2006;9(9):163-8. http://www.ajbrui.com. Cited 2 Aug 2017.

26. Osman MA, Abdelgadir AE. Detection of brucellosis in sheep intended for export and local slaughter in Khartoum State, Sudan. Afr J Microbiol Res [Internet]. 2012;6(39):6805-10. http://www.academicjournals.org/AJMR. Cited 3 Aug 2017.

27. Mellau L, Kuya S, Wambura P. Seroprevalence of brucellosis in domestic ruminants in the livestock-wildlife interface: a case study of Ngorongoro conservation area, Arusha, Tanzania. Tanzan Vet J. 2009;26(1):44-50.

28. El Kholy A, Gomaa H, Anany M, Abd El Rasheed E. Diagnosis of human brucellosis in Egypt by polymerase chain reaction. East Mediterr Heal J [Internet]. 2009;15(5). http://applications.emro.who.int/ emhj/1505/15_5_2009_1068_1074.pdf?ua=1.Cited 3 Aug 2017.

29. Muma J, Samui K, Siamudaala V, Oloya J, Matope G, Omer M, Munyeme M, Mubita C, Skjerve E. Prevalence of antibodies to Brucella spp. and individual risk factors of infection in traditional cattle, goats, and sheep reared in livestock-wildlife interface areas of Zambia. Trop Anim Heal Prod. 2006;38:195-206.

30. Mikolon AB, Garner IA, Hietala SK, de Anda JH, Pestaña EC, Hennager SG, Edmondson AJ. Evaluation of North American antibody detection tests for diagnosis of brucellosis in goats evaluation of North American antibody detection tests for diagnosis of brucellosis in goats. J Clin Microbiol. 1998;36(6):1716-22.

\section{Submit your next manuscript to BioMed Central and we will help you at every step:}

- We accept pre-submission inquiries

- Our selector tool helps you to find the most relevant journal

- We provide round the clock customer support

- Convenient online submission

- Thorough peer review

- Inclusion in PubMed and all major indexing services

- Maximum visibility for your research

Submit your manuscript at www.biomedcentral.com/submit
BioMed Central 